\title{
Germline and somatic c-met mutations in multifocal/bilateral and sporadic papillary renal carcinomas of selected patients
}

\author{
ALESSANDRO SALVI ${ }^{1}$, ELEONORA MARCHINA ${ }^{1}$, ANNA BENETTI ${ }^{2}$, PIERGIOVANNI GRIGOLATO ${ }^{2}$, \\ GIUSEPPINA DE PETRO ${ }^{1}$ and SERGIO BARLATI ${ }^{1}$ \\ Divisions of ${ }^{1}$ Biology and Genetics, Department of Biomedical Sciences and Biotechnology, IDET \\ Centre of Excellence and ${ }^{2}$ Pathologic Anatomy, University of Brescia, I-Brescia 25123, Italy
}

Received March 4, 2008; Accepted April 24, 2008

\section{DOI: 10.3892/ijo_00000006}

\begin{abstract}
Papillary renal carcinoma (PRC) comprises about $10 \%$ of all kidney epithelial tumors. Familiar/hereditary papillary renal carcinomas (HPRCs) have been described, but the majority of cases seem to be sporadic. HPRC is characterized by the predisposition to develop bilateral, multifocal renal tumors. Activating mutations in the tyrosine kinase domain (TK) of the hepatocyte growth factor (HGF) receptor, c-met, have been identified in both hereditary and sporadic PRC. The main aim of this study was to examine a family with no history of PRC in which the proband was a female patient affected by multiple and bilateral PRC at early onset. DNA mutation analysis has been performed by direct sequencing of exons 14-21 of c-met gene which include the TK domain. The proband displayed the germline c-met missense mutation g.3522G $\rightarrow \mathrm{A}$ in exon 16 . Two other family members were found to carry the same mutation. The mutation analysis extended to 15 selected patients, allowed to identify the first case of an Italian patient affected by PRC displaying the somatic missense mutation $\mathrm{g} .3997 \mathrm{~T} \rightarrow \mathrm{C}$ located in exon 19 of c-met. The mutation frequency of the selected-based population of PRC patients in this report was $12.5 \%$. Furthermore, the phosphorylated c-met expression detected by immunohistochemistry in PRCs with germline/somatic or no c-met mutation, supports the concept that c-met activation may occur in PRC oncogenesis by c-met mutations and/or c-met over-expression.
\end{abstract}

\section{Introduction}

Renal cell carcinomas (RCCs) represent $85 \%$ of all kidney malignancies and this incidence increases between the fifth

Correspondence to: Professor Giuseppina De Petro, Division of Biology and Genetics, Department of Biomedical Sciences and Biotechnology, University of Brescia, Viale Europa n. 11, I-25123 Brescia, Italy

E-mail: depetro@med.unibs.it

Key words: c-met mutation, hereditary papillary renal carcinoma, immunohistochemistry and seventh decades of life. RCC affects approximately 150,000 people worldwide each year and is responsible for nearly 78,000 deaths annually. RCCs include different types of tumors: $75 \%$ are clear cells, $10 \%$ are papillary (PRC) type 1 and type $2,5 \%$ are chromophobe, the remaining $10 \%$ being made up of collecting duct and medullary tumors $(1,2)$. There are mutations in different genes that occur in the different kidney cancer types: VHL (von Hippel-Lindau, tumor suppressor gene) for clear cell, c-met (oncogene) for papillary type 1; FH (fumarate hydratase that seems to act as tumor suppressor gene) for papillary type 2; BHD (Birt Hogg Dubé, tumor suppressor gene) for chromophobe $(1,3)$. The subdivision of PRC into type 1 and type 2 was first introduced by Delahunt and Eble (4). PRC cancers can develop into a sporadic non-inherited form as well as hereditary forms. Somatic and germline mutations in the c-met oncogene were identified in sporadic and hereditary form of PRC (5-8) (HPRC: OMIM 164860). c-met protein is composed of a $50-\mathrm{kDa} \alpha$-chain linked by disulfide bonds with a $145-\mathrm{kDa}$ $\beta$-chain that has an intracellular tyrosine kinase (TK) domain. c-met belongs to the family of TK, the members of which play important roles in stimulating intracellular signalling cascades (9). Most c-met mutations that correlate to PRC are missense, located within the TK. These c-met mutations are responsible for the constitutive activation of the signalling cascades that lead to a loss of control of cellular proliferation ability and contribute to cell transformation $(1,7)$.

For Italian PRC cases, Olivero et al (10) studied 9 PRC cases, describing for the first time the germline mutation g. 3522G $\rightarrow$ A (V1110I) in exon 16 in 1 family. Schmidt et al (7) studied a second Italian family with this germline c-met mutation: 9 members had renal carcinoma, and 10 carriers were identified. Fischer et al (11) found duplication of the same parental c-met allele of chromosome 7 in multiple tumors in two members of another HPRC Italian family, but they did not find any c-met germline mutations.

In this report, we present a family with mutation V1110I in the c-met exon 16. We performed the DNA mutation analysis of the TK domain of c-met by direct sequencing of DNA from 15 other PRC patients. We also carried out immunohistochemistry for c-met and phosphorylated c-met (p-c-met) of some PRC tissue sections to examine the implications of c-met activation in PRC oncogenesis (3). 
Table I. Characteristics of the patients in this study.

\begin{tabular}{ccccccc}
\hline N & Patient & Age at diagnosis (years) & Sex & Unilateral or bilateral & Left or right & PRC type \\
\hline 1 & PRC 1 & 78 & M & U & L & 2 \\
2 & PRC 2 & 78 & M & U & L & 1 \\
3 & PRC 3 & 70 & M & U & L & 2 \\
4 & PRC 4 & 52 & M & U & R & 2 \\
5 & PRC 5 & 60 & F & U & L & 1 \\
6 & PRC 6 & 76 & M & U & R & 2 \\
7 & PRC 7 & 49 & M & U & R & 2 \\
8 & PRC 8 & 78 & F & U & R & 2 \\
9 & PRC 9 & 65 & M & U & U & 1 \\
10 & PRC 10 & 50 & M & U & R & 2 \\
11 & PRC 14 & 56 & M & U & L & 1 \\
12 & PRC A & 54 & M & U & R & 2 \\
13 & PRC D & 55 & F & B & L/R & 1 \\
14 & PRC F & 36 & M & U & R & 1 \\
15 & KD1 & 42 & 47 & & &
\end{tabular}

PRC, papillary renal carcinoma; KD, kidney; M, male; F, female.

\section{Patients and methods}

Patients and DNA extraction. Sixteen cases of sporadic PRC were included in this study of c-met mutations. The PRC diagnosis was based on pathology and medical reports by hematoxylin and eosin (H\&E) staining, as well as evaluating the type 1 or type 2 architecture (4). Tissue section slides (6- $\mu \mathrm{m}$ thick) from paraffin blocks of tumors and correspondent peritumoral tissues of all cases were obtained from the paraffin archives of the II Division of Pathologic Anatomy of the University of Brescia. KD1, KD1.F (KD1's father), KD1.S (KD1's sister) and KD2 patients' peripheral blood were also available. De-paraffinization of the paraffin-embedded tissue sections was performed by xylene followed by rehydration with $100 \%$ and $75 \%$ ethanol. Tissues lysis were performed using proteinase $\mathrm{K}(20 \mathrm{mg} / \mathrm{ml})$ at $52^{\circ} \mathrm{C}$ overnight. Phenol: chloroform:isopropanol alcohol (Invitrogen Life Technologies, Carlsbad, CA) at 25:24:1 was used for the centrifugation phase separation. The supernatant was kept, and equal volumes of chloroform were added, mixed, and centrifuged at 12,000 x g for $5 \mathrm{~min}, 3 \mathrm{M}$ sodium acetate was added to the supernatant, then $1 \mathrm{Vol}$ of isopropanol was added and incubated overnight at $-20^{\circ} \mathrm{C}$. After DNA precipitation, the supernatant was discarded and the precipitate washed once with $75 \%$ ethanol. The extracted DNA was collected and after being completely dried, the DNA was resuspended in an adequate volume of sterile TE buffer.

DNA from peripheral blood leukocytes of the KD1, KD1.F, KD1.S and KD2 patients was extracted using GeneCatcher gDNA 3-10 ml Blood kit (Invitrogen) according to the manufacturer's instructions. DNA concentration was determined using Nanodrop spectrophotometer. c-met mutation analysis. Nucleotides were numbered according to the NCBI accession no. J02958. The exons 14-21 which included the c-met TK domain, were amplified by PCR using the previously described primer pairs (9). Amplicons were visualized, purified and sequenced using ABI PRISM 310 Genetic Analyzer (Applied Biosystems, CA, USA).

Immunohistochemistry. Tissue sections (5- $\mu \mathrm{m}$ thick) were de-paraffinized in xylene, rehydrated in ethanol, incubated in $0.3 \% \mathrm{H}_{2} \mathrm{O}_{2}$ in methanol for 20 min to block endogenous peroxidase activity; $3 \%$ BSA was used to block non-specific staining. The sections were washed with $1 \mathrm{X}$ PBS and incubated with rabbit anti-c-met $(1: 50 \mathrm{v} / \mathrm{v})$ or rabbit anti-phospho-c-met $\left(\mathrm{pY}^{1003}\right)(12)(1: 50 \mathrm{v} / \mathrm{v})$, overnight (Santa Cruz Biotechnology, Biosource, CA, USA). The biotinylated secondary antibodies were added for $15 \mathrm{~min}$ (Super Sensitive IHC Detection Systems, BioGenex, San Ramon, CA, USA). After extensive washing, the sections were incubated with horseradish peroxidase complex (ABC complex) for $15 \mathrm{~min}$. The chromogen DAB was used to localize the peroxidase in tissues. The slides were counterstained with H\&E and analyzed with an optical microscope.

\section{Results}

Tissue sections from 15 sporadic single and 1 multiple and bilateral PRC type 1 and type 2 were tested for mutations in the TK domain of c-met gene, in particular, exons from 14 to 21 were sequenced. The selected cases included 12 unrelated Italian males and 4 unrelated Italian females, with a mean age at diagnosis of $59 \pm 3.4$ years ranging between 36 and 78 years old (Table I). The proband KD1 (female, 42-year- 
A

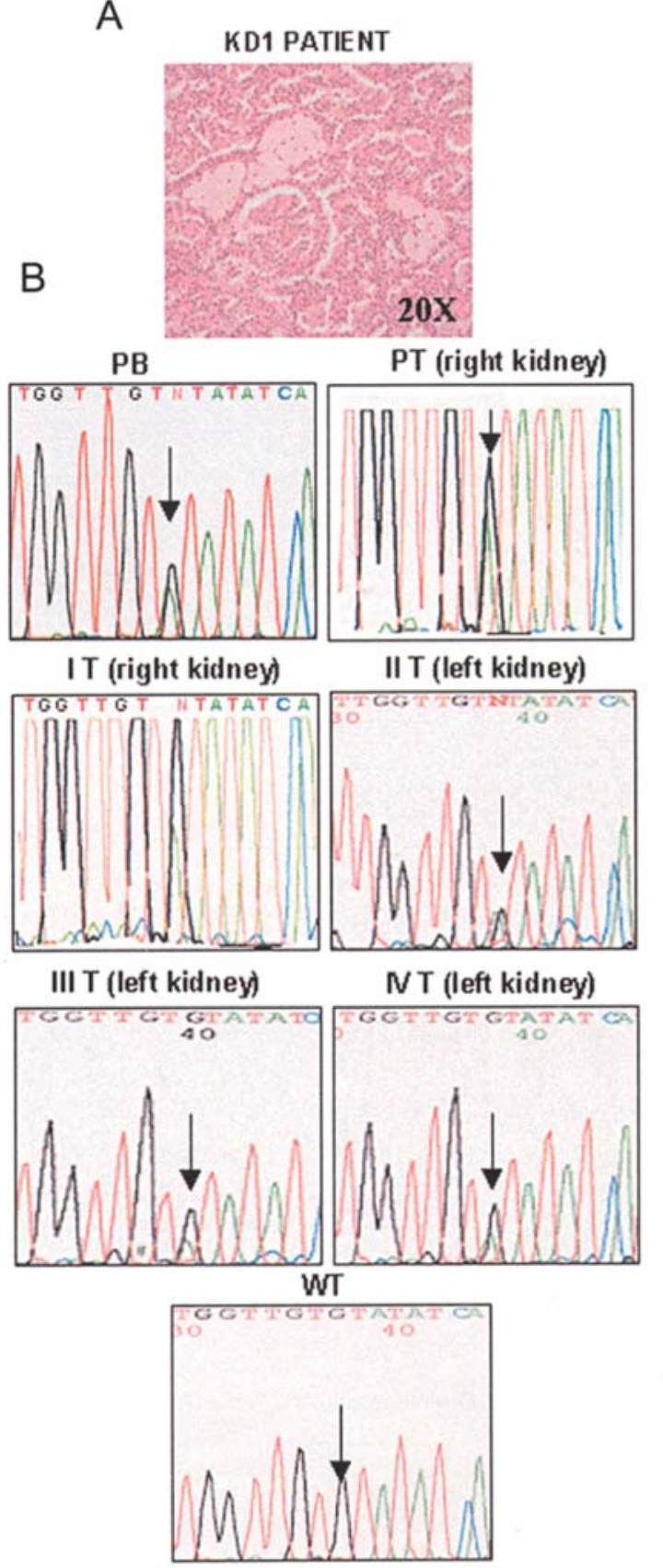

Figure 1. (A) KD1 patient histology, H\&E. (B) KD1 patient DNA sequencing analysis. PB, peripheral blood; PT, peri-tumoral tissue; and T, tumoral tissues, (I; II, III, IV indicate 4 different tumoral nodules; the arrow indicates missense mutation site; $\mathrm{G}$ is wild-type, $\mathrm{A}$ is mutant).

old) had multiple and bilateral PRC at early onset, without any family history of renal neoplasia. At the histological analysis, this PRC was composed of small basophilic cells with scant cytoplasm and low grade nuclei (Fig. 1A). A heterozygous missense mutation that consisted of a $G \rightarrow A$ transition at nucleotide 3522 in exon 16 of c-met was found in the patient ( $\mathrm{G}$ is wild-type, $\mathrm{A}$ is mutant; Fig. 1B). This missense mutation resulted in an amino acid change from valine to isoleucine (V1110I). This mutation was detected in KD1 proband at the peripheral blood DNA level and both tumor and peri-tumoral tissue DNA demonstrated the germline type of mutation (Fig. 1B) (4 different tumoral
A

KD1 family

I

II

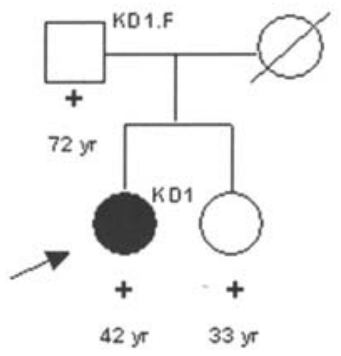

KD1.F

B

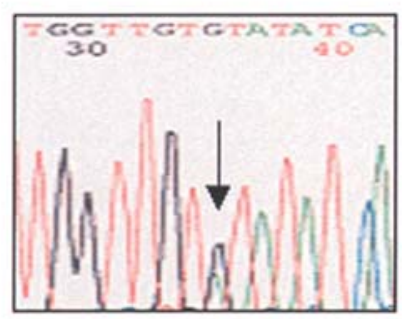

KD1.S

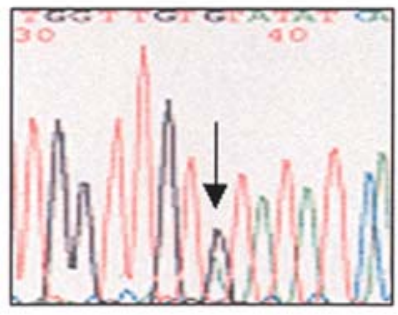

WT

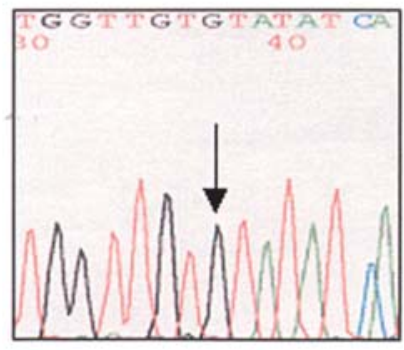

Figure 2. (A) Pedigree of the KD1 family with HPRC. The arrow indicates the proband. The solid symbol represents a subject affected by HPRC. Diagonal slashes indicate deceased members. + , indicates genetic positive testing for mutations in c-met exon 16. (B) KD1.F and KD1.S DNA sequencing analysis (the arrow indicates missense mutation site; $\mathrm{G}$ is wild-type, $\mathrm{A}$ is mutant).

nodules were analysed; 1 localized in the right kidney and the other 3 in the left kidney). In order to identify mutation carriers of the KD1 family (Fig. 2A), the sequencing of c-met exon 16 from the peripheral blood of KD1's father (KD1.F; 72 years old) and KD1's sister (KD1.S; 33 years old) were carried out. KD1.F had a surgical resection of a gastrointestinal stromal tumor (GIST) at 26 with no history of renal cancer. (No more information either from instrumental examination or paraffin embedded samples were available as the surgery had been performed in 1962). Both KD1.F and KD1.S displayed c-met missense mutation V1110I in heterozygosis (Fig. 2B). At the time of c-met mutation analysis, both 
A PRC5 PATIENT

B

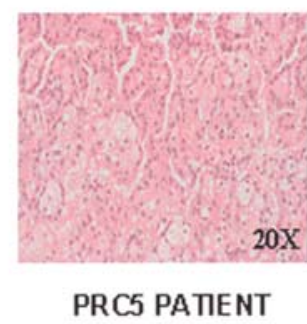

$T$

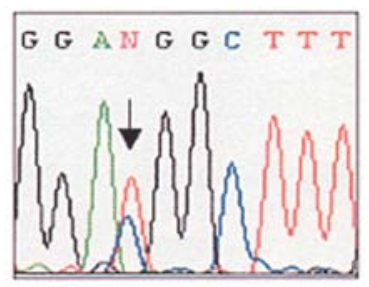

PT

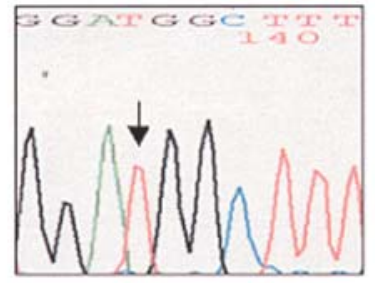

Figure 3. (A) PRC5 patient histology, H\&E. (B) Direct DNA sequencing analysis of PRC5 patient (the arrow indicates the missense mutation site; $\mathrm{T}$ is wild-type, $\mathrm{C}$ is mutant).
KD1.F and K D1.S were asymptomatic and only KD1.S accepted to undergo kidney instrumental examination which resulted to be negative for kidney cancer.

The PRC5 patient (male, 60-year-old) had a left kidney PRC of about $4 \times 3.5 \times 3 \mathrm{~cm}$. Histologically, this tumor was composed of small cells with scanty, pale and basophilic cytoplasm. The cells formed a single layer on the papillae. Psammoma bodies and macrophages were abundant (Fig. 3A). In the tumoral tissue of the PRC5 patient, a base substitution with a $\mathrm{T} \rightarrow \mathrm{C}$ transition in heterozygosis at nucleotide 3997 in exon 19 of c-met (Fig. 3B) was identified ( $\mathrm{T}$ is wild-type, C is mutant). This missense mutation resulted in an amino acid change from methionine to threonine (M1268T). The mutation was not identified in the peri-tumoral tissue DNA, confirming the somatic type of mutation (Fig. 3B). The other 14 patients did not have any mutations in exons 14-21 of c-met and so, the overall frequency of c-met mutations was $12.5 \%$ (2/16). Three polymorphisms previously described were also identified (SNP NCBI accession no. rs 41736, rs 2023748, rs 41737, respectively located in exons 20, 21 and 21). To determine the expression level of c-met and phosphorylated-c-met (p-c-met), immunohistochemical analysis was performed on KD1 (nodules I and II), PRC5 and PRC9 tissue sections (Fig. 4) (the only specimens available for this type of analysis). c-met was found highly expressed in the cytoplasm and the cell membrane of the tumor portion cells of the three samples analysed (Fig. 4, panel 1A-C; panel $2 \mathrm{I}$ and L). In the normal kidney tissues, c-met immune-
2

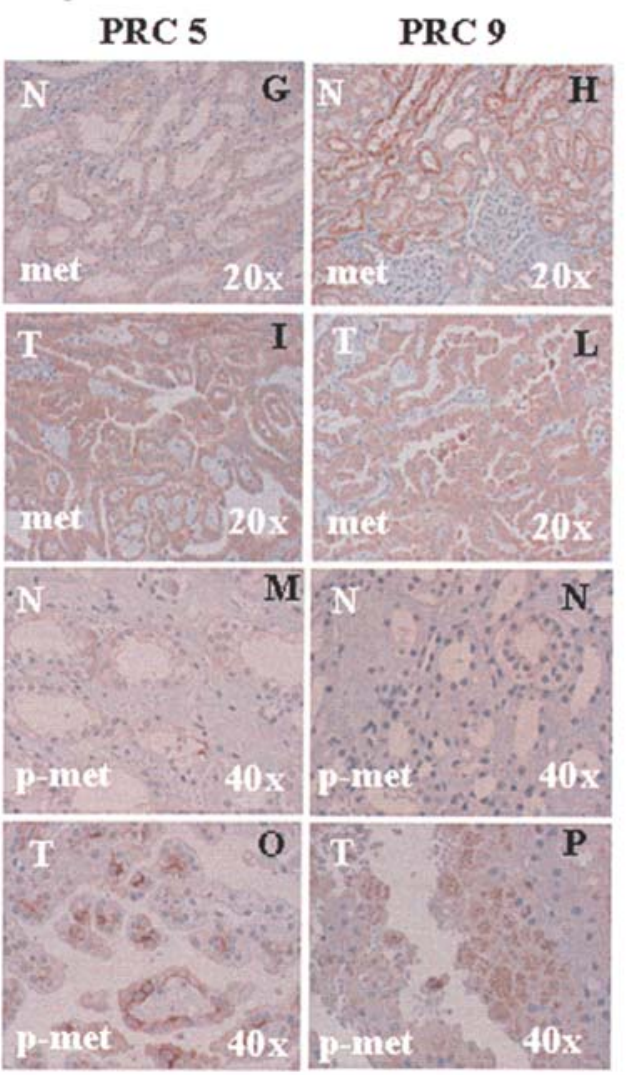

Figure 4. Panel 1, c-met and phospho-c-met immunohistochemical analysis of tissue sections of the KD1 patient (nodule I and nodule II); N, normal kidney tissue; T, tumor tissue. Panel 2, c-met and phospho-c-met immunohistochemical analysis of tissue sections of PRC 5 and PRC 9 patients; N, normal kidney tissue; $\mathrm{T}$, tumor tissue. 
staining was found in the cytoplasm of the tubular cells (Fig. 4, panel $1 \mathrm{~B}$; panel $2 \mathrm{G}$ and $\mathrm{H}$ ). A higher expression level of phospho c-met was also detected in the tumor portion of the specimens from patients KD1, PRC 5 and PRC 9 (Fig. 4, panel 1D; panel $2 \mathrm{O}$ and $\mathrm{P}$ ) compared to their normal counterparts (Fig. 4, panel 1F; panel $2 \mathrm{M}$ and N), where only a few weakly positive tubular cells were detected. In the PRC9 tumor tissue section, granular cytoplasmic staining patterns for $\mathrm{p}$ c-met were observed (Fig. 4, panel 2P). For KD1 nodule tissues, p-c-met was detected in the cell nuclear compartment of nodule I cells (Fig. 4, panel 1E) and in both cytoplasmic and nuclear compartments of the nodule II cells (Fig. 4, panel 1D).

\section{Discussion}

The main purpose of this study was to determine whether the proband KD1 with multiple and bilateral PRC was a carrier of c-met mutation. Indeed, it is well known that HPRC, with a predisposition to develop multiple, bilateral papillary renal neoplasms (13), and a subset of sporadic PRCs could be caused by activating mutations in the c-met oncogene. The c-met mutation analysis of the KD1 proband was made after a surgical tumor resection and allowed the identification of a germline mutation V1110I located in exon 16. As previously reported, this mutation was located in the glycine-rich subdomain of the ATP-binding site highly conserved in protein kinases and it conferred transforming properties to the c-met gene $(6,10)$. The KD1 patient and her sister inherited the mutated allele from their father (KD1.F) who had no history of PRC during his life, but had a GIST (gastrointestinal stromal tumor) surgical resection at the age of 26. GISTs are the most common mesenchymal tumors of the gastrointestinal tract and it is possible that the mutation V1110I in c-met gene played a role in the early onset of the GIST in KD1.F. Indeed, GIST can be caused by mutations of the TK receptor c-kit, causing its constitutive activation (14) and this gene belongs to the same TK family as c-met. Furthermore, a homologous mutation V1110I was found in the TK v-erbB gene coding the EGF receptor (13) involved in the progression of several malignancies. In addition, Lim and Wojcik (15) described a case of concomitant development of PRC and GIST, hypothesizing that the c-met and c-kit oncogenes might be activated by the same mechanism. To our knowledge this is the third Italian family (reported in the literature) with HPRC and carrying the germline mutation V1110I.

The c-met mutation analysis extended here to 15 selected Italian patients affected by PRC allowed us to identify the first Italian case with the somatic c-met mutation M1268T. This known c-met activating mutation (7) is located in a codon homologous to the mutation in the TK RET gene that causes multiple endocrine neoplasia type $2 \mathrm{~B}$ and sporadic medullary carcinoma of the thyroid gland (5). It is likely that this somatic mutation was selected during the PRC progression, possibly with other still unknown or known genetic lesions, was critical for the acquisition of the tumor phenotype.

It is known that the frequency of c-met mutations in PRC is low. Lindor et al (16) did not find germline mutations in any non-selected patients $(0 \% ; \mathrm{CI}=0-6.18)$ in 59 individuals in a study carried out between 1976 and 1997. Schimdt et al (6) reported a total of 17 mutations in 129 individuals (13\%).
Schmidt et al (7) extended previous studies, bringing the number of HPRC families worldwide to $>30$. In this study, the frequency of c-met mutations was $12.5 \%(2 / 16)$ and although the number of cases was low, the percentage agreed with that reported by Schimdt et al (6). Obviously, it would be interesting to increase the number of worldwide and/or Italian patients to confirm this point.

For c-met protein expression, the immunohistochemical analysis carried out on KD1 and PRC 5 tissue sections (with germline and somatic mutations respectively) and on PRC 9 sections (with no mutations) showed that c-met was highly expressed in tumor tissues. As expected, c-met staining was localized in tubular cells in normal kidney tissues (17). Furthermore, p-c-met was generally over-expressed in tumor tissue sections compared to normal kidney tissue sections. Even if only related to three PRC cases these observations indicate that c-met activation that, very likely occurred by an over-expression mechanism is implicated in PRC oncogenesis $(18,19)$. This is so, even without activating c-met mutations, at least those located in the c-met TK domain. Other observations related to the sub-cellular localization in nuclear compartments of PRC cells, as well as a granular cytoplasmic pattern of c-met staining, have also been reported in melanoma and lung cancers $(12,20)$.

The diagnosis of PRC associated to c-met mutations may be relevant in planning clinical follow-up after surgery and applying the most appropriate therapy. This could be administration of TK inhibitors combined with conventional chemo- and radio-therapies. In this context we know that: i) the c-met kinase inhibitor SU11274 exhibits a selective inhibition pattern toward c-met mutated variants; the L1213V and $\mathrm{Y} 1248 \mathrm{H}$ variants are resistant to SU11274, while H1112Y and M1268T (present as somatic mutation in PRC 5) are sensitive to this TK inhibitor (21); ii) an in vitro radiation of pancreatic cancer cells may cause an increase in c-met expression (22). Thus, further study could improve the development of molecular approaches for c-met targeting in cancer (i.e., RNAi or antisense c-met silencing) (23). Decreasing the expression level of wild-type or mutated c-met before applying cytotoxic therapies could enhance the radiation-induced cell kill and also might prevent c-met dependent invasion and metastasis of cancer cells that could be promoted by radiation.

\section{Acknowledgments}

The authors thank Dr Robert Coates (University of Brescia) for linguistic revision of the manuscript.

\section{References}

1. Linehan WM, Vasselli J, Srinivasan R, Walther MM, Merino M, Choyke P, Vocke C, Schmidt L, Isaacs JS, Glenn G, Toro J, Zbar B, Bottaro D and Neckers L: Genetic basis of cancer of the kidney: disease-specific approaches to therapy. Clin Cancer Res 10: S6282-S6289, 2004.

2. Pavlovich CP and Schmidt LS: Searching for the hereditary causes of renal-cell carcinoma. Nat Rev Cancer 4: 381-393, 2004.

3. Linehan WM, Pinto PA, Srinivasan R, Merino M, Choyke P, Choyke L, Coleman J,Toro J, Glenn G, Vocke C, Zbar B, Schmidt LS, Bottaro D and Neckers L: Identification of the genes for kidney cancer: opportunity for disease specific targeted therapeutics. Clin Cancer Res 13: 671-679, 2007. 
4. Delahunt B and Eble JN: Papillary renal cell carcinoma: a clinicopathologic and immunohistochemical study of 105 tumors. Mod Pathol 10: 537-544, 1997.

5. Schmidt L, Duh FM, Chen F, Kishida T, Glenn G, Choyke P, Scherer SW, Zhuang Z, Lubensky I, Dean M, Allikmets R, Chidambaram A, Bergerheim UR, Feltis JT, Casadevall C, Zamarron A, Bernues M, Richard S, Lips CJ, Walther MM, Tsui LC, Geil L, Orcutt ML, Stackhouse T, Lipan J, Slife L, Brauch H, Decker J, Niehans G, Hughson MD, Moch H, Storkel S, Lerman MI, Linehan WM and Zbar B: Germline and somatic mutations in the tyrosine kinase domain of the MET proto-oncogene in papillary renal carcinomas. Nat Genet 16: 68-73, 1997.

6. Schmidt L, Junker K, Nakaigawa N, Kinjerski T, Weirich G, Miller M, Lubensky I, Neumann HP, Brauch H, Decker J, Vocke C, Brown JA, Jenkins R, Richard S, Bergerheim U, Gerrard B, Dean M, Linehan WM and Zbar B: Novel mutations of the MET proto-oncogene in papillary renal carcinomas. Oncogene 18: 2343-2350, 1999.

7. Schmidt LS, Nickerson ML, Angeloni D, Glenn GM, Walther MM, Albert PS, Warren MB, Choyke PL, TorresCabala CA, Merino MJ, Brunet J, Berez V, Borras J, Sesia G, Middelton L, Phillips JL, Stolle C, Zbar B, Pautler SE and Linehan WM: Early onset hereditary papillary renal carcinoma: germline missense mutations in the tyrosine kinase domain of the met proto-oncogene. J Urol 172: 1256-1261, 2004.

8. Takaki Y, Furihata M, Yoshikawa C, Kishida T, Yao M and Shuin T: Sporadic bilateral papillary renal carcinoma exhibiting c-met mutation in the left kidney tumor. J Urol 163: 1241-1242, 2000.

9. Duh FM, Scherer SW, Tsui LC, Lerman MI, Zbar B and Schmidt L: Gene structure of the human MET proto-oncogene. Oncogene 15: 1583-1586, 1997.

10. Olivero M, Valente G, Bardelli A, Longati P, Ferrero N, Cracco C, Terrone C, Rocca-Rossetti S, Comoglio PM and Di Renzo MF: Novel mutation in the ATP-binding site of the MET oncogene tyrosine kinase in a HPRCC family. Int J Cancer 82: 640-643, 1999.

11. Fischer J, Palmedo G, von Knobloch R, Bugert P, Prayer-Galetti T, Pagano F and Kovacs G: Duplication and overexpression of the mutant allele of the MET proto-oncogene in multiple hereditary papillary renal cell tumours. Oncogene 17: 733-739, 1998.

12. Nakamura Y, Niki T, Goto A, Morikawa T, Miyazwa K, Nakajima $\mathbf{J}$ and Fukayama M: c-met activation in lung adenocarcinoma tissues: an immunohistochemical analysis. Cancer Sci 98: 1006-1013, 2007.
13. Zbar B, Glenn G, Merino M, Middelton L, Peterson J, Toro J, Coleman J, Pinto P, Schmidt LS, Choyke P and Linehan WM: Familial renal carcinoma: clinical evaluation, clinical subtypes and risk of renal carcinoma development. J Urol 177: 461-465, 2007.

14. Fletcher JA and Rubin BP: KIT mutations in GIST. Curr Opin Genet Dev 17: 3-7, 2007.

15. Lim JC and Wojcik EM: Fine-needle aspiration cytology of papillary renal cell carcinoma: the association with concomitant secondary malignancies. Diagn Cytopathol 34: 797-800, 2006.

16. Lindor NM, Dechet CB, Greene MH, Jenkins RB, Zincke MT, Weaver AL, Wilson M, Zincke $\mathrm{H}$ and Liu W: Papillary renal cell carcinoma: analysis of germline mutations in the MET proto-oncogene in a clinic-based population. Genet Test 5: 101-106, 2001.

17. Pisters LL, El-Naggar AK, Luo W, Malpica A and Lin S-H: c-met proto-oncogene expression in benign and malignant human renal tissue. J Urol 158: 724-728, 1997.

18. Sweeney P, El-Naggar AK, Lin S-H and Pisters LL: Biological significance of c-met over expression in papillary renal cell carcinoma. J Urol 168: 51-55, 2002.

19. Miyata Y, Kanetake H and Kanda S: Presence of phosphorylated hepatocyte growth factor receptor/c-met is associated with tumour progression and survival in patients with conventional cell carcinoma. Clin Cancer Res 12: 4876-4881, 2006.

20. Saitoh K, Takahashi H, Sawada N and Parsons PG: Detection of the c-met proto-oncogene product in normal skin and tumours of melanocytic origin. J Pathol 174: 191-199, 1994.

21. Berthou S, Aebersold, Schmidt LS, Stroka D, Heigl C, Streit B, Stalder D, Gruber G, Liang C, Howlett AR, Candinas D, Greiner RH, Lipson KE and Zimmer Y: The Met Kinase inhibitor SU11274 exhibits a selective inhibition pattern towards different receptor mutated variants. Oncogene 23: 5387-5393, 2004.

22. Qian LW, Mizumoto K, Inadome N, Nagai E, Sato N, Matsumoto K, Nakamura T and Tanaka M: Radiation stimulates HGF receptor/c-Met expression that leads to amplifying cellular response to HGF stimulation via upregulated receptor tyrosine phosphorylation and MAP kinase activity in pancreatic cancer cells. Int J Cancer 104: 542-549, 2003.

23. Salvi A, Arici B, Portolani N, Giulini SM, De Petro G and Barlati S: In vitro c-met inhibition by antisense RNA and plasmid-based RNAi down-modulates migration and invasion of hepatocellular carcinoma cells. Int J Oncol 31: 451-460, 2007. 